\title{
Sexos, sexualidades e gêneros: monstruosidades no currículo da Educação Sexual ${ }^{1}$
}

\author{
Sexes, sexualities and genders: monsters in \\ Sexual Education curriculum
}

\author{
Jimena Furlani
}

\section{RESUMO}

Apresento um exercício de análise cultural, a partir da frase "Que bicho é esse?" - do livro paradidático infantil (Lopes, 2000) para se referir a "sexo" e "sexualidade". Problematizo as potencialidades reflexivas da Educação Sexual tendo como referência a "Pedagogia dos Monstros" (Cohen, 2000) e a "desconstrução" como método analítico, articulando-as com teorizações nos campos dos Estudos Culturais e Feministas, sob a

\footnotetext{
${ }^{1}$ Esclareço que este artigo teve como orientações de composição e escrita as normas da ABNT. Entretanto, assumo um "modo feminista de escrever", ou seja: 1) opondo-me a qualquer linguagem sexista que tenha a forma masculina como regra geral... Explicito o masculino e o feminino ao longo do texto, ora com linguagem inclusiva (ex.: meninos e meninas), ora, quando possível, utilizando termos neutros em gênero (ex.: criança). Não utilizarei "homem" para me referir à humanidade. 2) Escrevo na primeira pessoa, colocando-me dentro do texto. Assumo, portanto, uma postura contrária à suposta "neutralidade da ciência moderna", uma vez que os Estudos Feministas (e suas (seus) estudiosas (os)) são assumidamente interessadas (os) numa sociedade menos desigual em gênero. 3) Nas citações bibliográficas, ao longo do texto, visibilizo a autoria citando o prenome e o sobrenome dos/as autores/as quando da sua primeira aparição. Devo, também, informar que este artigo foi apresentado no GE 23: Gênero, Sexualidade e Educação, ANPED - 2005. Texto originário da tese de doutorado "O Bicho vai pegar! - um olhar pós-estruturalista à Educação Sexual a partir de livros paradidáticos infantis" (UFRGS, 2005), sob orientação da Prof. Dra. Guacira Lopes Louro.

2 Doutora em Educação. Professora da Universidade do Estado de Santa Catarina (UDESC). Membro do Núcleo de Estudos da Sexualidade (NES/UDESC) e do Grupo de Estudos em Educação e Relações de Gênero (GEERGE/UFRGS). f2jf@pobox.udesc.br.
} 
perspectiva pós-estruturalista de análise. Na Escola "os sexos", "as sexualidades" e "os gêneros" podem ser pensados como "monstros curriculares", assim como todo assunto marcado pela polêmica, pela provisoriedade, pela normalização. Como fenômeno metafórico cultural "os monstros" subordinam-se aos padrões hegemônicos da cultura normativa ao mesmo tempo em que resistem a eles. Essa resistência permite que, na Educação Sexual, os processos constituintes da normalidade e da desigualdade possam ser permanentemente postos em questão.

Palavras-chave: Educação sexual; Educação, Gênero e sexualidade; Currículo e formação de educadoras/res.

\begin{abstract}
I present an exercise of cultural analysis using the sentence "What is this thing?", from the children's textbook (Lopes, 2000) to refer to "sex" and "sexuality". I discuss the reflexive potential in Sexual Education, having as a reference Pedagogy of the Monsters (Cohen, 2000) and the "deconstruction" as an analytical method, associating them with theories in the fields of Cultural Studies and Feminist Studies, under the post-structuralist perspective of analysis. At school, "the sexes", "the sexualities" and "the genres" can be thought as "curricular monsters", as well as all the subjects marked by controversy, fleetness, normalization. As a cultural metaphoric phenomenon, "the monsters" subordinate themselves to the hegemonic standards of the normative culture at the same time they resist to them. This resistance allows the constituent processes of normality and the inequality in Sexual Education can be permanently questioned.
\end{abstract}

Keywords: Sex Education; Education, Gender and Sexuality; Curriculum and Formation of Educators. 
No contexto da Educação Sexual em todos os níveis, repensar os gêneros, as sexualidades, as políticas de identidade e o currículo escolar tem sido um exercício produtivo de articulação teórica entre os Estudos Culturais e os Estudos Feministas sob orientação da perspectiva pósestruturalista de análise. Uma "retribuição teórica" que tem apontado para a conexão entre os aspectos constitutivos e políticos dos sujeitos, suas identidades e as representações sociais que os constituem através de processos discursivos impregnados de desiguais relações de poder.

O papel que a Escola assume nesse cenário pode ser visto, não apenas como importante, mas como estratégico na medida em que se constitui num local potencialmente explicitador e questionador das complexas formas pelas quais as identidades culturais são construídas, articuladas, experienciadas, transgredidas e re-articuladas no âmbito do social. O currículo escolar, portanto, é central na construção das diferenças e das identidades. ${ }^{3}$ Não apenas definido como a relação de disciplinas, conteúdos, atividades, metodologias, avaliações, regulamentos... O currículo é "todo um sistema de comportamento e de valores (...) todo o tipo de aprendizagens e de ausências que os alunos obtêm como conseqüência de estarem sendo escolarizados", toda e

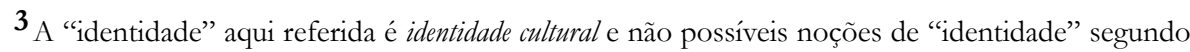
teorizações dos campos da psicologia. Segundo Tomas Tadeu da Silva (2000a), "de acordo com a teorização pós-estruturalista que fundamenta boa parte dos Estudos Culturais contemporâneos, a identidade cultural só pode ser compreendida em sua conexão com a produção da diferença, concebida como um processo discursivo" (Silva, 2000a, p. 69). Sexo, gênero, sexualidade, raça, etnia, nacionalidade, classe, religião, geração etc. são exemplos de identidades culturais.

4 Representação: “(...) na análise cultural, mais recente, refere-se às formas textuais e visuais através das quais se descrevem os diferentes grupos culturais e suas características. No contexto dos Estudos Culturais, a análise da representação concentra-se em sua expressão material como 'significante': um texto, uma pintura, um filme, uma fotografia. Pesquisam-se aqui, sobretudo, as conexões entre identidade cultural e representação, com base no pressuposto de que não existe identidade fora da representação" (Silva, 2000a, p. 97). 
qualquer "experiência vivida pelo aluno" (Sacristán, 1995, p. 86 e p. 88). O currículo é representação. ${ }^{4}$

No Brasil, no âmbito do currículo escolar oficial, a Educação Sexual não é uma disciplina obrigatória, mas sim uma temática a ser transversalizada nos diversos conteúdos, em que o livro paradidático, por exemplo (do qual emprestarei uma única frase para o exercício desconstrutivo pretendido neste artigo), constitui-se num recurso metodológico constante e imprescindível no dia-a-dia da sala de aula. Entretanto, esses livros não são somente integrantes curriculares... Eles são também artefatos culturais. Seu texto (verbal e ilustrativo) produz e veicula representações de gênero e de sexualidade... "Ensina" modo(s) de "ser masculino" e de "ser feminino", formas (ou a forma) de viver as sexualidades. Essas representações têm efeitos de verdade e contribuem para produzir sujeitos. A articulação entre currículo escolar e significados culturais, bem como a problematização relacional de marcadores sociais (sobretudo o gênero e a sexualidade), a partir desses livros, adquire fundamental importância na Educação Sexual que me parece ser a mais produtiva.

Parece-me importante, portanto, discutir como as identidades culturais são produzidas nas práticas sociais através de um processo de produção da diferença e, mais particularmente, como podem ser apresentadas/representadas (as identidades e as diferenças) nos materiais pedagógicos. Sabemos que todo processo e toda dinâmica de formação de identidades referem-se à existência de um "outro" (que não sou eu; que é diferente de mim), o que torna identidade e alteridade componentes necessariamente inseparáveis. Assim, a identidade só fará sentido numa cadeia discursiva de diferenças: "o que ela é" será totalmente dependente "daquilo que ela não é". A diferença cultural dependerá de inúmeros processos de exclusão, de vigilância de fronteiras, de estratégias de divisão que, em última análise, definem hierarquias, escalas valorativas, sistemas 
de categorização... Aspectos esses indispensavelmente questionáveis na Educação Sexual que busca problematizar o sexismo, a misoginia, a homofobia, as diversas formas de preconceito e exclusão.

Pela perspectiva pós-estruturalista, analisar o caráter do currículo a partir dos Estudos Culturais é conceder ênfase aos efeitos da linguagem e do discurso. É destacar "as estreitas conexões entre a natureza construída do currículo e a produção de identidades culturais e sociais”, bem como "as diversas formas de conhecimento corporificadas no currículo", entendendo os saberes (científico ou do senso comum) como resultante de um "processo de criação e interpretação social" (Silva, 2001, p. 135). Ao falar em construção, essa perspectiva refere-se à construção discursiva. Não nega a materialidade dos corpos; entretanto, se questiona como, culturalmente, são atribuídos significados às características corporais e como, essa nomeação, essa atribuição de nomes, subordina, hierarquiza e define desigualdades. A noção de discurso é oriunda de Michel Foucault (1993) e corresponde às premissas conceituais genéricas que geralmente caracterizam instituições (médica, religiosa, pedagógica, midiática) ou correntes de pensamento (epistemes) e seus enunciados (como aqueles que compõem o machismo, a xenofobia, a homofobia, o sexismo).

Concordo com Guacira Louro (2000, p. 66): a linguagem é componente central nos processo sociais de construção da sexualidade (e diria também, do gênero, do sexo etc.). Nesse sentido, o que busco neste artigo é apresentar à Educação Sexual uma possibilidade de visibilizar o potencial didático da desconstrução a partir de um exercício de análise cultural. ${ }^{5}$ Questionarei a linguagem utilizada numa coleção de livros paradidáticos (Lopes, 2000) e seus possíveis efeitos sobre a constituição dos sujeitos e das identidades. Partirei da pergunta que a autora faz ao seu público quando inicia o primeiro livro: Que bicho é esse? Sexo e sexualidade. ${ }^{6}$ 


\section{PEDAGOGIAS DAS SEXUALIDADES E DOS GÊNEROS NA EDUCAÇÃO SEXUAL}

Que representações estariam envolvidas quando, no âmbito da pedagogia infantil (ou até mesmo adulta), temas como sexo e sexualidade são comparados a "bichos"? Quais os possíveis efeitos pedagógicos de se fazer a pergunta: "Que bicho é esse?" e de se obter como resposta: "Sexo e Sexualidade"?

É a partir desses questionamentos que procurarei apresentar as potencialidades da "desconstrução" como uma análise possível à Educação Sexual. Tendo a frase "Que bicho é esse?" como ponto de partida, buscarei desconstruir o texto, ou seja, explorá-lo, etimológica e sociologicamente. O objetivo da desconstrução é restaurar o estranhamento com o texto e mostrar a força da linguagem na construção dos sujeitos, das identidades

\footnotetext{
5 Termo freqüente nas ciências sociais e humanas, "desconstrução" foi empregada pelo filósofo francês Jacques Derrida (1930-2004) e caracteriza o modo pelo qual um texto pode ser lido e explicitado em suas contradições e irredutibilidades. Um procedimento comum da desconstrução é apontar as oposições binárias presentes na trama textual. Todo texto comporta interpretações que, à primeira vista, parecem irreconciliáveis (Derrida, 2001). Para Setu-Co Yamashiro (2004), "desconstruir um texto é desfazer as fronteiras entre as oposições, sobretudo a oposição sujeito/objeto, subvertendo a ordem e os valores hierárquicos tradicionais contidos nelas". O significado do texto é mutável, uma vez que depende da interpretação atribuída por cada leitor. João Ferreira (2001) entende a desconstrução como "um modo de leitura" onde o/a leitor/a pode/deve "subverter a intencionalidade artística do autor e desconstruir o texto a seu modo". A "desconstrução", como uma metodologia, é um processo que opera buscando "abrir" o sentido do texto, através de procedimentos como: inversão, deslocamento, análise, problematização, estranhamento, ironia.

6 Neste artigo, o exercício desconstrutivo parte da frase: "Que bicho é esse?". A autora Cida Lopes (2000) utiliza-se dessa expressão para se reportar a "sexo" e "sexualidade" numa coleção de livros paradidáticos de Educação Sexual infantil. A Coleção Sexo e Sexualidade foi lançada no Brasil em maio de 2000, pela Editora BrasiLeitura; hoje é editada pela TodoLivro. Apresenta 12 livros. Neste artigo, estou problematizando a estratégia lingüística usada no livro 1: Que bicho é esse? Sexo e sexualidade. Critérios para escolha da Coleção: apresenta grande aceitação de professoras(es), sendo altamente difundida e utilizadas em escolas públicas e particulares; é distribuída em todo território nacional; os exemplares podem ser adquiridos separadamente ou no conjunto, o que facilita sua comercialização e dispersão.
} 
culturais, das diferenças, das desigualdades. "Não são os seres humanos que possuem linguagem, mas é a linguagem que nos possui”" (Yamashiro, 2004).

Em Lopes (2000), parece que o uso da palavra "bicho" não é sem propósito, na medida em que a autora procura mostrar, num primeiro momento, que as temáticas referidas (sexo e sexualidade) estão ausentes dos currículos escolares - ou seja, demonstrar que se constituem em uma questão "desconhecida". No entanto, que possíveis efeitos a representação adquire quando conduz as temáticas ao mundo fantasioso da bestialidade, dos monstros, das fábulas animalescas, ou seja, quando as trata como uma questão "assustadora"?

Entendo que a metáfora que se apresenta nesta pergunta/título permite-me considerar que na Escola, "sexo", "sexualidade" e, acrescento, "gênero", são assuntos, ao mesmo tempo, de difícil abordagem e de completo fascínio. Mexem com o pavor e o pânico das/os educadoras/res mais conservadoras/es e desatentas/os, ao mesmo tempo em que aguçam e estimulam desejos e prazeres de um mundo, para muitos, pouco explorado, desconhecido ou ignorado.

Os monstros, assim como figuras folclóricas, originam-se de um entendimento metafórico de algum momento social, de alguma passagem cultural, sendo, portanto, específicos de contextos históricos e locais. São muitos os monstros, materializados, corporificados em horrendas personagens, que flutuam na imaginação humana. Quer seja pela literatura universal, quer seja pela memória popular ou pelos registros potencializados nos artefatos da tecnologia moderna, o fato é que as representações da vida humana estão repletas de figuras mitológicas, ${ }^{7}$ personagens cinematográficas ${ }^{8}$ ou do folclore popular. ${ }^{9}$ Indispensáveis ao desejado "final feliz", em que deve triunfar o bem, os facínoras do roteiro tornam-se efetivamente maus, perversos e cruéis quando conseguem somar às qualidades perversas do seu caráter o aspecto materializado de uma monstruosidade aterrorizante, de uma anomalia, de uma aberração. 
Quer sejam tomados como identidades culturais (constituidoras dos sujeitos) ou como temáticas (à Educação Sexual), penso que "sexo", "sexualidade" e "gênero" podem ser pensados como monstros curriculares - assim como todo e qualquer assunto marcado pela polêmica, pela provisoriedade, pela normatização, pelo olhar moral, pela regulação social. Para Jeffrey Jerome Cohen (2000, p. 27), “os monstros devem ser analisados no interior da intrincada matriz de relações (sociais, culturais e litero-históricas) que os geram".

\section{QUANDO A RESISTÊNCIA \\ VISIBILIZA A PLURALIDADE}

No entendimento dos Estudos Culturais, sob a perspectiva pósestruturalista, mormente no que se refere ao caráter instável e construcionista das identidades, os "sexos", os "gêneros" e as "sexualidades" também se aproximam de um aspecto presente na análise dos monstros quando vistos como fenômeno metafórico cultural. Estou referindo-me à:

recusa a fazer parte "da ordem classificatória das coisas" (...) - os monstros em geral (...) são híbridos que perturbam, híbridos cujos corpos externamente incoerentes resistem a tentativas para incluí-los em qualquer estruturação sistemática. E,

\footnotetext{
7 Como a Anaconda (cobra enorme e voraz); Cérbero (o cão de três cabeças que esteve presente no filme Harry Potter e a pedra filosofal); ciclopes (gigantes com um único olho no centro da testa); grifo (tipo de cavalo alado, metade águia, metade leão e orelhas de cavalo); minotauro (corpo humano e cabeça de touro); unicórnio (cavalo branco dotado de chifre no meio da cabeça).

8 Como a bolha assassina; Chucky (boneco assassino); Frankenstein (homem construído com pedaços de cadáveres costurados); Freddy Krueger (assassino que ressuscita depois de ser queimado vivo); Godzilla (dinossauro mutante, destruidor); Jason (assassino com mascara branca) da série Sexta-Feira Treze; vampiros; lobisomem; zumbis (mortos-vivos); bruxas; abominável homem das neves; o incrível Hulk; fantasmas; almas penadas.

9 Entre eles o Bicho-Papão; boitatá (gigantesca cobra de fogo); boto (peixe da Amazônia que se transforma num rapaz bonito); caipora (menino, de corpo cabeludo, montado num porco-domato); chupa-cabra; curupira (menino com pés virados para trás); ET de Varginha; mula-semcabeça; negrinho do pastoreio; onça-boi (onça pintada com patas de boi); saci-pererê.
} 
assim, o monstro é perigoso, uma forma - suspensa entre formas - que ameaça explodir toda e qualquer distinção

(Cohen, 2000, p. 30).

Essa possibilidade de transgredir a lógica de qualquer sistema conceitual é garantida pela própria existência do monstro que atuaria e se caracterizaria pela constante resistência e desaprovação a qualquer tipo de limite ou fronteira; resistiria a qualquer tipo de finalização ou engessamento identitário. Trazendo tais idéias para as discussões recentes acerca das sexualidades e dos gêneros, é possível questionar a restrição imposta pela tradição binária do pensamento ocidental, que considera, na constituição dos sujeitos, apenas "isto" ou "aquilo", ou seja, ou se é masculino ou feminino, homem ou mulher, heterossexual ou homossexual. No processo de construção das identidades, é possível considerar, também, a conjunção aditiva "e". O monstro é, dessa forma, a corporificação viva do fenômeno que Jacques Derrida (1973) chamou de 'o suplemento' - a lógica do 'isto OU aquilo' dá lugar ao raciocínio que admite 'isto E aquilo'. O aspecto eclético do monstro caminha ao encontro da perspectiva pós-estruturalista que revoluciona os métodos tradicionais de organizar o conhecimento (sobretudo o da lógica binária).

A partir dessa inferência, no contexto da Educação Sexual, talvez possamos pensar: Até que ponto as representações do preconceito e da discriminação sexual e de gênero encontram um considerável apoio na incapacidade de se admitir esta episteme aditiva (e não apenas a alternativa)? Ou seja, em que medida a incapacidade de reconhecer como igualmente válidas inúmeras outras possibilidades da vida sexual humana, bem como as diversas "transgressões" de fronteiras de gênero, tem sido usada para justificar a intolerância e a intransigência humanas? Penso que, sob esse enfoque, a metáfora do monstro nos permite, assim, ilustrar e perceber como bases argumentativas de um saber podem dificultar a 
compreensão e o respeito à multiplicidade sexual e de gênero em nossa cultura.

\section{QUANDO A MONSTRUOSIDADE \\ LEGITIMA A "VIOLÊNCIA"}

Outra contribuição à Educação Sexual, a partir da metáfora do monstro, é a utilização da lógica que instaura as diferenças culturais no acirramento do preconceito às identidades subordinadas. Parece-me fértil discutir o "processo pelo qual a exageração da diferença cultural se transforma em aberração monstruosa" (Cohen, 2000, p. 33). Por exemplo, a representação prévia de certa identidade como monstruosa e negativa, especialmente de identidades nacionais (mulçumanos, turcos, sérvios, judeus), por exemplo, tem sido usada, ao longo da história, tanto para justificar a diáspora quanto o extermínio desses grupos. ${ }^{11}$ Para a Educação Sexual, essa lógica (que no exemplo das identidades nacionais "legitima" a xenofobia) serve para o entendimento da homofobia. Sobretudo, quando, diante da representação "monstruosa" da identidade homossexual (ou de outra identidade sexual subordinada), algumas pessoas ou instituições assumem o papel de paladinos da justiça moral, como se estivessem fazendo um "favor social", "limpando" as ruas através de atos de violência verbal e/ou física dos monstros, dos maus elementos, dos depravados, daqueles que depõem contra a família e os bons costumes. Nesse caso, a representação monstruosa naturaliza a violência e a subjugação de um tipo de sujeito representado como diferente, como monstruoso, por outro tipo (o "normal") que é "autorizado" socialmente a cometer os atos de discriminação e preconceito.

${ }^{10}$ Estou considerando as várias formas que a violência pode assumir: física, moral, psicológica etc.

11 Para Cohen (2000), o ato de extermínio dessas populações consideradas "inferiores" seria considerado e significado como heróico por quem o praticasse (p. 33). 
O monstro surge no intervalo no qual a diferença é percebida como a divisão entre, de um lado, a voz que registra a "existência" do "diferente" e, de outro, o sujeito assim definido; o critério dessa divisão é arbitrário, e pode ir desde a anatomia ou a cor da pele até a crença religiosa, ao costume e à ideologia política

(Cohen, 2000, p. 44-45).

Louro (2004, p. 57), após afirmar como, em nossa sociedade, é "comum, compreensível e corriqueiro" que o sujeito homossexual seja desprezado, admitiu que a definição de seu atual objeto de estudo (a teoria queer) foi, além de uma escolha teórica, uma escolha política. A autora assume seu interesse em "compreender como se dá, nas instâncias a que chamamos pedagógicas, a reiteração" das posições-de-sujeito subordinados "e, para, além disso, pensar sobre o que pode ser feito para desestabilizar e desarranjar tais certezas". Parece-me que "desmontar", "desconstruir" o processo que constrói culturalmente "os monstros sociais" é parte de uma Educação Sexual que visa, sobretudo, a questionar os saberes "inquestionáveis" - aqueles que têm possibilitado hierarquias identitárias e o acirramento do preconceito de todas as ordens.

A destrutividade do monstro é realmente uma desconstrutividade: ele ameaça revelar que a diferença tem origem no processo e não no fato (e que o "ato" está sujeito a constante reconstrução e mudança)

(Cohen, 2000, p. 45).

Nesse processo de questionamento do caráter construído das identidades culturais, penso que podem (e devem) ser postos em questão

$12 \mathrm{Na}$ França Medieval, os mulçumanos foram caracterizados em figuras demoníacas, desprovidos de atributos humanitários. Uma representação cultural que "justificava" todas as formas de exclusão do que era tido como Oriental pelo Ocidente (Cohen, 2000, p. 33). 
não apenas as sexualidades, mas também os sexos e os gêneros, e especialmente a matriz biológica que os sustenta. Para isso, me parece produtivo assumir o conceito de gênero oriundo da problematização feminista pós-estruturalista, que tem privilegiado, segundo Dagmar Meyer (2003, p. 16), a “discussão de gênero a partir de - ou com base em abordagens que enfocam a centralidade da linguagem como locus de produção das relações que a cultura estabelece entre corpo, sujeito, conhecimento e poder". Nessa perspectiva, continua a autora afirmando que o corpo é igualmente um produto da cultura produzido em relações de poder (e não um dado essencial, universal e inquestionável). Todo e qualquer processo capaz de produzir distinções entre os gêneros, os sexos e as sexualidades é possível de ser analisado como invenção política, cultural e social. Os gêneros constituem e atravessam as instituições sociais e os diversos conhecimentos.

Todas as identidades sexuais subordinadas ou as "transgressões" de gênero, ao serem tidas socialmente como desviantes, podem ser vistas como "monstruosidades culturais". Assim, volto a associar a metáfora do monstro com a interdição sexual e de gênero numa cultura que, paradoxalmente, ao criar o monstro, descreve-o e associa-o a certa utilidade social. Geralmente, o monstro ajuda a demarcar aquilo que o social define como perigoso e proibido, ou seja, "as fronteiras que não podem - não devem - ser cruzadas" (Cohen, 2000, p. 43). Ao definir o que é monstruoso e interdito, o raciocínio binário demarca também, o que "é normal", permitido, autorizado socialmente. Nesse processo de demarcação da diferença, as identidades estabelecem uma dependência mútua: eu sou aquilo que você não é.

Para Silva (2000b, p. 80-81), “a identidade e a diferença são tão indeterminadas e instáveis quanto a linguagem da qual dependem", são resultantes de "um processo de produção simbólica e discursiva" mediado por relações de poder. Essas relações de poder estabelecem marcas que 
incluem/excluem, demarcam fronteiras, classificam, hierarquizam, normalizam. Os monstros (e por analogia, as identidades subordinadas), nessa relação mútua de explicitar a diferença, tornam-se paradoxalmente imprescindíveis à demarcação da identidade tida como hegemônica, como "normal", como straight. A identidade é relacional e "a diferença é estabelecida por uma marcaşão simbólica relativamente a outras identidades" (Woodward, 2000, p. 14). Portanto, para a demarcação social da identidade heterossexual é imprescindível a demarcação social da identidade homossexual, e vice-versa. O "monstro" precisa ser mantido discursivamente "vivo" para que a normalidade estabeleça seus limites e se instale no social.

\section{UTILIDADES SOCIAIS E EDUCACIONAIS DO "MONSTRO"}

Não há, na cultura ocidental, um personagem monstruoso que expresse, exclusivamente, a sexualidade ou o sexo. Entretanto, essas duas temáticas são tabus sociais suficientemente poderosos para constituir inúmeras metáforas moralistas e conservadoras, presentes nos personagens culturais corporificados em monstros, num estado simultâneo de interdição, repulsão e atração. Na cultura brasileira, por exemplo: о BОтO é um peixe da Amazônia que se transforma em um rapaz bonito, hábil dançarino, que conquista as mulheres para levá-las ao rio. A lenda do Boto é pretexto para as moças justificarem a gravidez fora do casamento, dizendo que ficaram grávidas dele; a MULA-SEM-CABEÇA é uma mulher malvada ou que namorou com um padre e que nas noites de quinta para sexta-feira se transforma. $\mathrm{O}$ encanto quebra-se caso alguém conseguir tirar o freio de ferro de sua cabeça, surgindo, em seu lugar, uma mulher arrependida; a PORCA DOS SETE LEITÕES, no folclore paulista, é a alma penada da mãe que provocou o aborto de sete fetos. Ela persegue maridos que ficam na rua fora de hora; o BOITATÁ é uma gigantesca cobra 
de fogo. Segundo a lenda, ela é a alma penada de um menino pagão ou de pessoas que cometeram incesto; o MATINTAPEREIRA é uma pequena coruja que canta à noite para anunciar a morte de uma pessoa. Faz parte da mitologia tupi. Pode ser também uma mulher grávida que abandona o feto. $^{13}$

Poderíamos pensar, afinal, parafraseando Jose Gil (2000, p. 174): "Qual é a função do monstro no pensamento simbólico? (...) O que é que se pensa quando se pensa na monstruosidade?". Penso que tal questionamento pode ser transferido à "sexualidade", como se ela fosse corporificada num ente, num ser. Quando o autor nos faz considerar que “o monstro é pensado como uma aberração da 'realidade' (...) um excesso de realidade" (Gil, 2000, p. 175), ele sugere que aí está implicada "a crença na 'necessidade da existência' da normalidade humana" (Gil, 2000, p. 175). É quase impossível não deixar de imaginar o quanto essa lógica estaria permeada nas representações culturais que a "sexualidade" tem adquirido nas sociedades ocidentais. Ela mesma (uma vida sexual ativa e diversa) seria vista como uma "dimensão humana monstruosa" quando analisamos a história, que por séculos, parece ter privilegiado muito o sexo reprodutivo confinado ao casamento cristão ou a castidade. Portanto, expressar uma ampla vida sexual, concebê-la em todas as fases da vida, admitir práticas sexuais distintas daquelas voltadas à reprodução, considerar a existência de uma subjetividade no prazer humano, entre outras coisas, tornariam a sexualidade, inquestionavelmente, "monstruosa".

É nesse sentido que Kathryn Woodward (2000, p. 10) vai afirmar que a construção da identidade é tanto um processo simbólico quanto um processo social que tem efeitos ou conseqüências materiais na vida dos

13 Informações deste parágrafo foram obtidas em: <www.guiadoscuriosos.com.br>, capturado em: 20 dez. 2003. 
sujeitos. Conseqüências e efeitos concretos, que, nesse caso, são os processos de regulação, normalização e fronteiras permitidas que se estabelecem sobre os gêneros e as sexualidades na vida dos sujeitos.

Dizem os estudiosos que é possível "ler as culturas a partir dos monstros que elas engendram" (Cohen, 2000, p. 25). O modo como cada sociedade gera, cria, constrói seus monstros está relacionado, diretamente, com os significados a eles atribuídos em relação ao objeto de que falam. É possível que "os sexos", "as sexualidades" e "os gêneros", se tiverem que ser abordados no contexto escolar, para muitos professores, professoras, direção, pais e mães, se constituam em verdadeiros bichosde-sete-cabeças. E aqui estou evocando não apenas a analogia com "algo de difícil solução", "um problema a ser resolvido”. Mas, também, estou operando com a compreensão de óbice, aquilo que obsta, que impede (a "tranqüilidade" no espaço escolar?); um empecilho, um estorvo (social?). Ou seja, são tanto assuntos (temáticas) quanto identidades culturais. Ambos incomodam, perturbam, importunam, causam preocupação, aborrecimentos, desgostos, irritação, exasperam a paz social, cultural e política. E, portanto, insisto, são verdadeiros "monstros do currículo escolar".

Certamente, a discussão da sexualidade na Escola fascina muitos e apavora outros tantos; ou talvez melhor seria dizer que ela fascina e apavora, ao mesmo tempo, a muitos. Mas vale registrar que o momento histórico em que vivemos se mostra mais favorável a essa discussão: a política educacional oficial estimula e recomenda; a demanda infantojuvenil "obriga"; pais e mães dividem-se entre a objeção, a indiferença e a manifestação favorável; professoras e professores definem-na como projeto político pessoal e imergem na Educação Sexual. A sexualidade viva, no contexto cultural, é cada vez mais assunto obrigatório na Escola, em todos os seus níveis. Quer queiramos ou não, tudo indica que "o bicho vai pegar". 


\section{REFERÊNCIAS}

COHEN, Jeffrey Jerome. A cultura dos monstros: sete teses. In: SILVA, Tomaz Tadeu da (Org.). Pedagogia dos monstros: os prazeres e os perigos da confusão de fronteiras. Belo Horizonte: Autêntica, p. 23-60, 2000.

DERRIDA, Jacques. Posições. Belo Horizonte: Autêntica, 2001.

DERRIDA, J. Gramatologia. São Paulo: Perspectivas, 1973.

FERREIRA, João. A desconstrução como estratégia de leitura do texto literário. 2001. Disponível em: <www.usinadeletras.com.br/exibelotext>. Acesso em: 29 out. 2004.

FOUCAULT, Michel. História da sexualidade: a vontade de saber. 11 ed. Rio de Janeiro: Graal, 1993. v. 1.

GIL, Jose. Metafenomenologia da monstruosidade: o devir-monstro. In: SILVA, Tomaz Tadeu da (Org.). Pedagogia dos monstros: os prazeres e os perigos da confusão de fronteiras. Belo Horizonte: Autêntica, p. 164-183, 2000.

LOPES, Cida. Coleção sexo e sexualidade. [S.L.] BrasiLeitura, [2000].

LOURO, Guacira Lopes. Corpo, escola e identidade. Educação \& Realidade, Porto Alegre, v. 25 (2), p. 59-75, jul./dez. 2000.

LOURO, Guacira Lopes. O corpo estranho: ensaios sobre sexualidade e teoria queer. Belo Horizonte: Autêntica, 2004.

MEYER, Dagmar Estermann. Gênero e educação: teoria e política. In: LOURO, G. L.; NECKEL, J.F.; GOELLNER, S.V. (Org.). Corpo, gênero e sexualidade: um debate contemporâneo na educação. Petrópolis, RJ: Vozes, 2003. p. 9-27.

SACRISTÁN, J. Gimeno. Currículo e diversidade cultural. In: SILVA, Tomaz Tadeu da \& Moreira, Antonio Flavio (Org.). Territórios Contestados: o currículo e os novos mapas políticos e culturais. Petrópolis, RJ: Vozes, 1995. p. 82-113.

SILVA, Tomaz Tadeu da. Teoria cultural e educação: um vocabulário crítico. Belo Horizonte: Autêntica, 2000a. 
SILVA, Tomaz Tadeu da (Org.). Identidade \& diferença. Petrópolis: Vozes, 2000b.

SILVA, Tomaz Tadeu da. Documentos de identidade: uma introdução às teorias do currículo. Belo Horizonte: Autêntica, 2001.

WOODWARD, Kathryn. Identidade e diferença: uma introdução teórica e conceitual. In: SILVA, Tomaz Tadeu da (Org.). Identidade \& diferença. Petrópolis: Vozes, 2000.

YAMASHIRO, Setu-Co. 2004. Desconstrução: a crítica que se pretende literatura. Revista Ângulo. Disponível em:

$<$ http://angulo.fatea.br/angulo_88/angulo88_artigo04.htm>. Acesso em: 29 out. 2004.

Recebimento: 02/06/2007

Aprovação: 22/09/2007

\section{Contato:}

Rua Saldanha Marinho, 196

Centro

Florianópolis - SC

Cep: 88045-010

f2jf@pobox.udesc.br 